\title{
Safety and feasibility of exhaled breath condensate collection in ventilated infants and children
}

\author{
W.G. Muller*, F. Morini ${ }^{\#}$, S. Eaton ${ }^{\#}$, M. Peters* and A. Jaffe*
}

ABSTRACT: The aim of this study was to develop a technique for the collection of exhaled breath condensate (EBC) from ventilated children and assess its safety and feasibility. Collection of EBC is used to investigate markers of oxidative stress in the lower airway. No studies have assessed its safety in ventilated children.

An in vitro model was developed by connecting a ventilator to an artificial lung; 14 clinical and ventilatory parameters were measured during EBC collection from ventilated children. Levels of 8isoprostane were measured following collection with and without humidification of the inhaled gas.

Amount of water vapour collected was linearly related to time and to minute ventilation in the in vitro model. EBC collections $(n=68)$ were made from ventilated children. In the nonhumidified group, the mean (range) positive end-expiratory pressure increased by $4.1 \%(2.8-5.5 \%)$ and the peak inspiratory flow decreased by $6.1 \%$ (11.0-1.3\%) during collection. Detectable levels of 8isoprostane were only found in 10 out of 18 nonhumidified EBC samples (median (range) $\left.4.7 \mathrm{pg} \cdot \mathrm{mL}^{-1}(0-5.8)\right)$.

Collection of exhaled breath condensate from ventilated infants and children is feasible and safe. Discontinuation of humidification is likely to be important in standardising the measurement of inflammatory parameters in exhaled breath condensate collected from ventilated children.

\section{KEYWORDS: Exhaled breath condensate, 8-isoprostane, safety, ventilation}

ung fluid contains many volatile and nonvolatile substances that may provide insight into the pathophysiology and progress of lung diseases [1]. At present, many difficulties are associated with collecting lung fluid, including the invasiveness of the procedure, additional dilution and uncertainty regarding the exact origin of collected fluid [2-5]. Therefore, evaluation of inflammatory markers and markers of oxidative stress in lung fluid currently remains a research tool. The development of noninvasive methods, such as collection of exhaled breath condensate (EBC), may be an important step towards a useful clinical tool to aid in the diagnosis of diseases such as asthma and assess the impact of treatment $[6,7]$. To date, most studies of lung fluid in ventilated patients have used bronchoalveolar lavage (BAL) or direct aspiration of lung epithelial lining fluid [8]. These approaches have limited utility due to their invasiveness and potential to cause transient inflammation [9]. A noninvasive tool, which provides an alternative method of measuring markers of inflammation in the airways of unstable patients, would be particularly useful for repeated or even continuous measurements.

EBC is obtained by cooling exhaled breath and condensing the water vapour in a collecting tube, at temperatures around or below freezing point [10]. It has been widely used to identify markers of airway inflammation and oxidative stress [6]; however, controversies exist regarding the interpretation of these findings [11]. Although increasingly used in nonventilated subjects [6], it is rarely used in ventilated adults [12-16] or children $[17,18]$. This may be due mainly to technical difficulties. There has been no consistent approach regarding humidification of the inhaled gas mix during collection of EBC in ventilated subjects. In some studies, EBC was collected without humidification, either perioperatively [16] or after stopping humidification $[13,19]$. Other investigators continued with humidification [14, 17]. Furthermore, these studies have used a variety of collection methods, such as immersing tubing in wet ice $[14,18]$ or using a commercially available polypropylene

\section{AFFILIATIONS}

*Portex Anaesthesia, Intensive Therapy and Respiratory Medicine Unit, and

\# Dept of Paediatric Surgery, Institute of Child Health and Great Ormond Street Hospital for Children National Health Service Trust, London, UK.

CORRESPONDENCE

A. Jaffe

Portex Respiratory Medicine Group Level 6

Cardiac Wing

Great Ormond Street Hospital for Children and Institute of Child Health Great Ormond Street London WC1N 3JH UK

Fax: 442078298634

E-mail: ajaffe@doctors.org.uk

Received:

May 312005

Accepted after revision:

April 122006

\section{SUPPORT STATEMENT}

Research at the Institute of Child Health and Great Ormond Street Hospital for Children National Health Service Trust (London, UK) benefits from research and development funding from the Department of Health (London, UK). F. Morini receives support from the Eugenio Litta Foundation (Geneva,

Switzerland). 
collection tube surrounded by a pre-cooled aluminium sleeve at $-20^{\circ} \mathrm{C}$. (RTube; Respiratory Research, Inc., Charlottesville, VA, USA) [17]. A standardised approach to EBC collection in children does not exist, but is clearly needed for the interpretation and comparison of results [20]. Safety also plays an important role as collection of EBC becomes widely used. BARALDI et al. [21] demonstrated that EBC collection was safe in nonventilated children with acute asthma, but little is known about the safety of EBC collection in ventilated subjects. MOLONEY et al. [16] described its use in 26 ventilated adults without observing adverse effects. To the present authors' knowledge, there are no published data regarding its safety in ventilated paediatric subjects, and little is also known about the influence of ventilatory parameters on the amount and composition of collected condensate [22-24].

The aims of the present study were to develop a technique for collecting EBC from ventilated infants and children and to assess its safety and feasibility. Various biomarkers of airway inflammation have been measured in EBC $[1,14]$. Isoprostanes, such as 8-isoprostane, are prostanoid compounds formed from lipid peroxidation and reflect oxidant stress. In order to further assess the feasibility of collecting EBC from ventilated children, the effect of humidified and nonhumidified EBC on 8isoprostane measurement was assessed.

\section{METHODS}

\section{Collection of exhaled breath condensate}

An EBC collecting device (EcoScreen; Jaeger, Würzburg, Germany) was connected to the expiratory limb of the ventilatory circuit using straight connectors (code 1949/1970; Intersurgical ${ }_{\ltimes}$, Wokingham, UK). In order to make adjustments for the nonstandardised size of the mouthpiece of the EcoScreen (isolation adaptor in/ex valve (No 706343), Jaeger), the connectors were gently heated and moulded to fit. The

a)

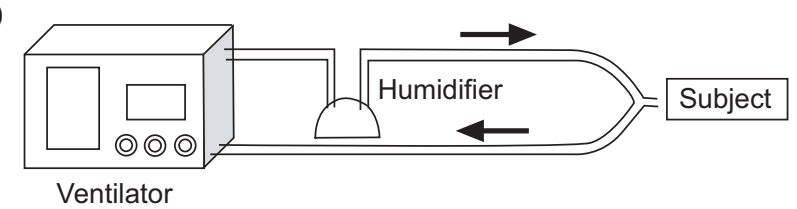

b)

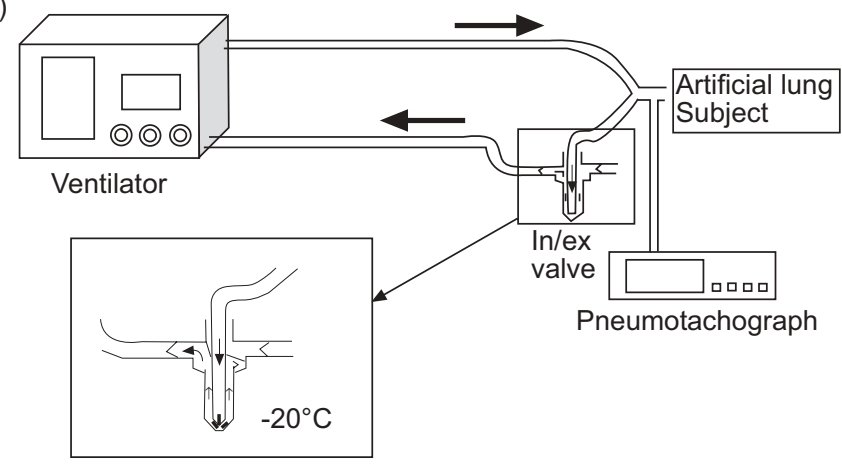

FIGURE 1. Ventilatory circuits: a) normal; and b) adapted, with the isolation adaptor in/ex valve inserted in the expiratory limb and a pneumotachograph inserted at the end of the endotracheal tube to measure flow, pressure and exhaled carbon dioxide. Only the expiratory pathway of the in/ex valve is required in ventilated patients and the gas flow is demonstrated with arrows. distance from the endotracheal tube was kept as short as possible $(\sim 50 \mathrm{~cm})$ in order to reduce the dead space (fig. 1$)$.

\section{In vitro model}

Previous studies have suggested that $3-4 \mathrm{~mL}$ EBC is needed for analysis of inflammatory markers using enzyme immunoassays and mass spectrometry. In order to determine the influence of time and minute ventilation $\left(V^{\prime} \mathrm{E}\right)$ on the amount of EBC recovered, an in vitro model was developed. The EcoScreen was attached to a ventilatory circuit with humidification using an artificial lung (Test lung 190; Siemens Medical Solutions, Erlangen, Germany) and a Servo 900C ventilator (Siemens-Elma, Solna, Sweden). Pressure-control settings similar to those used in ventilated children were used: maximal inspiratory pressure $(P \mathrm{I}, \max ) 20 \mathrm{cmH}_{2} \mathrm{O}$, peak endexpiratory pressure (PEEP) $4 \mathrm{cmH}_{2} \mathrm{O}$, respiratory frequency 20 breaths $\cdot \mathrm{min}^{-1}$, and inspiratory time $25 \%$, with no gas flow between breaths. Water vapour was collected for 15, 30 and $45 \mathrm{~min}$. Based on the results from this experiment, a $30-\mathrm{min}$ collection time was chosen to determine the influence of $V^{\prime} \mathrm{E}$ on the amount of condensate. For this purpose, a volume-control mode was selected and $1 \mathrm{~L} \cdot \mathrm{min}^{-1}$ incremental $V^{\prime} \mathrm{E}$ ranging 1$10 \mathrm{~L} \cdot \mathrm{min}^{-1}$ were delivered over a $30-\mathrm{min}$ collection period. All measurements were made in triplicate and averaged.

\section{Assessment of safety in vivo}

Subjects

Subjects aged $0-18$ yrs requiring conventional ventilation were recruited over a 12-month period from the Neonatal and Paediatric Intensive Care Unit of Great Ormond Street Hospital for Children (London, UK). Those subjects who had undergone laryngotracheal surgery were excluded due to the potential increase in upper airway inflammation. Children receiving high-frequency oscillation were also excluded as it was not possible to use identical equipment for collection and monitoring in these patients.

The ethics committee of the Institute of Child Health and Great Ormond Street Hospital for Children National Health Service Trust (London, UK) approved the study. Written consent was obtained by the investigators from the parents or legal guardians of the subjects.

\section{Measurements}

Respiratory frequency, $V^{\prime} \mathrm{E}$, inspiratory and expiratory tidal volume $(V \mathrm{~T})$, peak inspiratory flow (PIF), peak expiratory flow (PEF), PI,max PEEP and end-tidal carbon dioxide tension were recorded continuously using a $\mathrm{CO}_{2} \mathrm{SMOPlus!} \mathrm{analyser}$ (Novametrix Medical Systems, Wallingford, CT, USA). The $\mathrm{CO}_{2} \mathrm{SMOPlus!} \mathrm{measures}$ flow, pressure and capnography continuously via a disposable fixed-orifice differential-pressure flow sensor connected between the endotracheal tube and the ventilator circuit.

Cardiac frequency, mean blood pressure, arterial oxygen saturation and fraction of inspired oxygen $\left(\mathrm{FI}, \mathrm{O}_{2}\right)$ were also recorded. Intracranial pressure was additionally recorded in those subjects with intracranial pressure monitors following head trauma.

These parameters were recorded for $10 \mathrm{~min}$ prior to connection of the EcoScreen, then for $30 \mathrm{~min}$ following attachment to the 


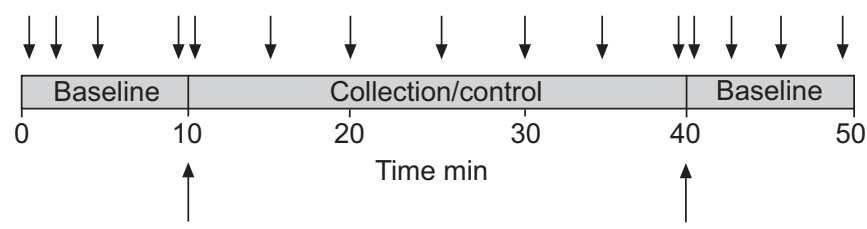

FIGURE 2. Study protocol for analysis of safety parameters. Exhaled breath condensate (EBC) was collected for $30 \mathrm{~min}$ (start and end indicated by upward vertical arrows). Baseline measurements were recorded for $10 \mathrm{~min}$ before and after EBC collection. Downward vertical arrows indicate the 1-min time intervals during which ventilatory and clinical parameters were measured. In the control group, the ventilatory circuit was briefly disconnected at 10 and 40 min (upward vertical arrows).

ventilatory circuit and finally for a further $10 \mathrm{~min}$ following disconnection. The data were collected at several time points (fig. 2). Control data, without collecting EBC, were obtained for a further $50 \mathrm{~min}$ in the same subjects. During this period, the ventilator tubing was briefly disconnected and reconnected at 10 and $40 \mathrm{~min}$ to simulate attachment and removal of the EcoScreen. Subjects were randomised to either EBC collection or disconnection (control) first using a random number generator. In a subgroup of subjects, the measurements were repeated immediately following the humidification study, using a dry circuit in order to assess the impact of dilution from humidification of the inhaled gases (nonhumidified EBC) (fig. 3). The subjects who were studied in the absence of humidification were chosen based on physician assessment of their predicted ability to tolerate collection without humidification.

\section{Detection of 8-isoprostane}

EBC from 30-min collections at $-10^{\circ} \mathrm{C}$ with humidification of the inhaled gas mix continued (humidified EBC) and nonhumidified EBC were frozen immediately after collection and stored at $-80^{\circ} \mathrm{C}$. Quantification of 8-isoprostane was performed using a specific enzyme immunoassay kit (Cayman Chemical, Ann Arbor, MI, USA). A sample of sterile water for inhalation

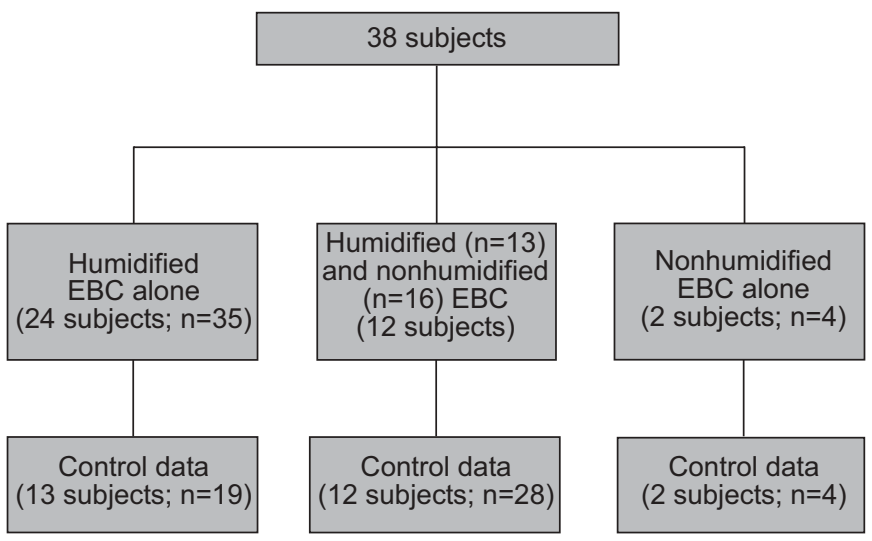

FIGURE 3. Collections $(n=68)$ of exhaled breath condensate (EBC; 48 humidified and 20 nonhumidified) were made from 38 subjects. Some subjects underwent more than one EBC collection. Control data, without collection of EBC, were obtained randomly (51 times) before or after collection of EBC in the same subjects.

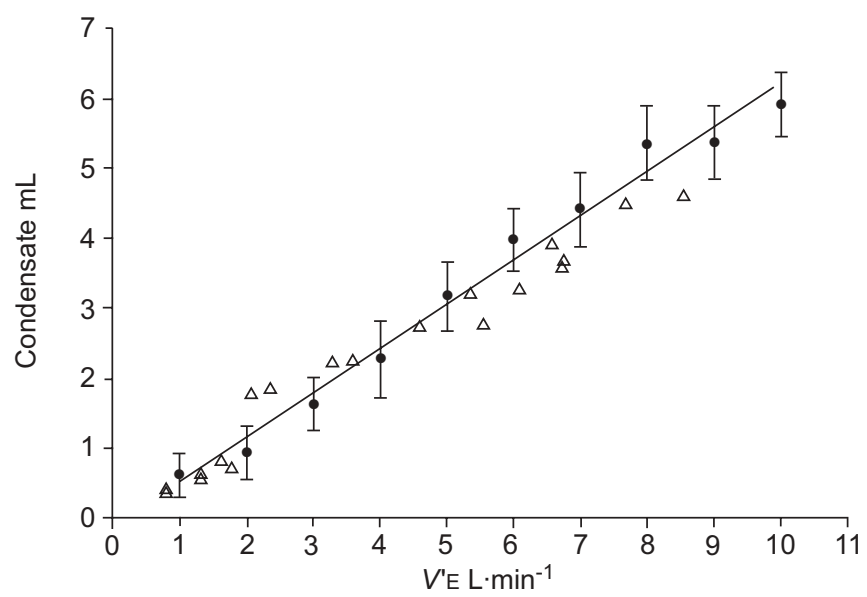

FIGURE 4. Relationship between minute ventilation $\left(V^{\prime} E\right)$ and amount of condensate collected. $\bullet$ : water vapour collected using an artificial lung in a ventilatory setting; $\triangle$ : exhaled breath condensate from ventilated subjects. Data were measured in triplicate; vertical bars represent 95\% confidence interval. $r^{2}=0.98$.

from the humidification reservoir was taken before it entered the ventilatory circuit and used as a control.

\section{Chemical methods}

The enzyme immunoassay is based on competition between an 8-isoprostane-acetylcholinesterase conjugate and 8-isoprostane for a limited number of 8-isoprostane-specific rabbit antiserum binding sites. The concentration of 8-isoprostane is determined spectrophotometrically, and is inversely proportional to the amount of free 8-isoprostane in the sample. All samples were analysed in triplicate. The reliable limit of detection of the assay is $3.9 \mathrm{pg} \cdot \mathrm{mL}^{-1}$. All values below this were recorded as zero.

\section{Statistics}

The 14 clinical and ventilatory parameters were converted to natural logarithms in order to achieve a normal distribution and then multiplied by 100 . The difference between two paired transformed values, once multiplied by 100 , corresponds closely to the percentage effect, as defined by 100(difference/ mean) [25].

Mean measurements before and after connecting the EcoScreen served as baseline. A paired t-test was used to compare the baseline data before and after collection of EBC and also to compare mean measurements during EBC collection (or control) with baseline measurements. Analysis of all individual measurements, using repeated-measures ANOVA with a post hoc test for linear trend, was also performed to examine any gradual change that may have occurred. The KruskalWallis test was used to analyse the 8-isoprostane results. A pvalue of $<0.05$ was regarded as significant.

\section{RESULTS \\ In vitro}

Collection of water vapour in a humidified ventilator circuit using an artificial lung model showed a linear relation between collection time and amount of collected water vapour $\left(\mathrm{r}^{2}=0.99\right.$; $\mathrm{p}<0.0001$; data not shown). The observed PEF in the circuit 


\begin{tabular}{|c|c|c|c|}
\hline \multirow[t]{2}{*}{ TABLE 1} & \multirow[b]{2}{*}{ Humidification } & \multirow[b]{2}{*}{ No humidification } & \multirow[b]{2}{*}{ Control } \\
\hline & & & \\
\hline Subjects $n_{1}$ & $36^{\#}$ & 14 & 27 \\
\hline Studies $\mathrm{n}_{2}$ & 48 & 20 & 51 \\
\hline Age yrs & $2.4(0-16.9)$ & $3.5(0.3-16.9)$ & $3.5(0-16.9)$ \\
\hline Weight kg & $12(1.7-75)$ & $15(4.1-75)$ & $15(2.0-75)$ \\
\hline Males/females $n_{1}$ & $21 / 15$ & $10 / 4$ & $19 / 8$ \\
\hline Lung pathology $n_{1}\left(n_{2}\right)$ & $25(36)$ & $11(12)$ & $21(41)$ \\
\hline Pneumonia & $5(8)$ & $3(4)$ & $4(11)$ \\
\hline PPHN & $3(3)$ & $1(1)$ & $2(4)$ \\
\hline Aspiration pneumonia & $6(11)$ & $2(3)$ & $8(16)$ \\
\hline Sepsis-related RF & $2(6)$ & $1(1)$ & $1(3)$ \\
\hline Pneumonitis & $2(2)$ & $1(1)$ & $1(2)$ \\
\hline TOF & $2(3)$ & 0 & $1(2)$ \\
\hline $\mathrm{CDH}$ & $1(1)$ & 0 & 0 \\
\hline Asthma & $3(4)$ & $1(1)$ & $4(5)$ \\
\hline CLD & $3(8)$ & $2(3)$ & $2(9)$ \\
\hline Bronchiolitis & $2(3)$ & $1(1)$ & $2(4)$ \\
\hline Tr lung contusion & $1(2)$ & $1(2)$ & $1(2)$ \\
\hline Head trauma $n_{1}\left(n_{2}\right)$ & $6(7)$ & $5(6)$ & $5(6)$ \\
\hline \multicolumn{4}{|c|}{ 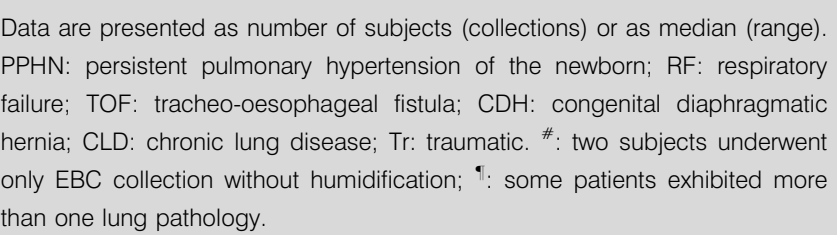 } \\
\hline
\end{tabular}

was $10 \mathrm{~L} \cdot \mathrm{min}^{-1}$ and the expiratory $V \mathrm{~T}$ was $159 \mathrm{~mL}$. Based on this experiment, a collection time of $30 \mathrm{~min}$ was then used to determine the influence of $V^{\prime} \mathrm{E}$ on the amount of water vapour collected. Again a linear increase was observed $\left(\mathrm{r}^{2}=0.98\right.$; $\mathrm{p}<0.0001$; fig. 4). Blockage of the collection system by ice was only observed for collection times of $>2 \mathrm{~h}$ in the in vitro model.

\section{In vivo}

Thirty-eight ventilated subjects (median (range) age 1.5 yrs (016.9 yrs); median (range) weight $10.3 \mathrm{~kg}$ (1.7-75 kg)) underwent a total of 68 EBC collections. Collections of EBC were made with humidification of the ventilatory circuit $(n=48)$ and with no humidification $(n=20)$. Two of the 38 subjects underwent only nonhumidified EBC collection (fig. 3). Control data before or after EBC collection were obtained for 51 EBC collections (27 subjects). Patient characteristics are shown in table 1.

The amount of EBC collected is shown in relation to $V^{\prime} \mathrm{E}$ in figure 4 for the 20 subjects who underwent discontinuation of humidification during sampling. There was a linear relationship between the amount of EBC collected and $V^{\prime} \mathrm{E}\left(\mathrm{r}^{2}=0.96\right.$; $\mathrm{p}<0.0001)$.

The types of ventilator and modes of ventilation used are summarised in table 2.

The results for each of the 14 parameters measured during the $30 \mathrm{~min}$ of EBC collection are shown as percentage changes

\begin{tabular}{|c|c|c|c|c|}
\hline \multirow[t]{2}{*}{ TABLE 2} & \multicolumn{4}{|c|}{$\begin{array}{l}\text { Ventilator and mode of ventilation in all children } \\
\text { undergoing exhaled breath condensate } \\
\text { collection with and without humidification }\end{array}$} \\
\hline & & Humidification & No humidification & Control \\
\hline \multicolumn{5}{|l|}{ Ventilator ${ }^{\#}$} \\
\hline Siemens S & vo i & 5 & 2 & 6 \\
\hline Siemens S & vo 300/300A & 18 & 12 & 27 \\
\hline Draeger ba & ylog 8000plus & 16 & 2 & 10 \\
\hline SLE 2000 & & 7 & 0 & 3 \\
\hline Evita 4 Dra & & 1 & 4 & 5 \\
\hline Infant Bear & & 1 & 0 & 0 \\
\hline Total & & 48 & 20 & 51 \\
\hline \multicolumn{5}{|c|}{ Ventilation mode } \\
\hline PRVC & & 6 & 5 & 10 \\
\hline SIMV & & 19 & 2 & 11 \\
\hline IMV & & 5 & 0 & 2 \\
\hline VS & & 9 & 8 & 14 \\
\hline PS & & 1 & 1 & 4 \\
\hline VC & & 2 & 0 & 2 \\
\hline $\mathrm{PC}$ & & 5 & 0 & 4 \\
\hline BiPAP/ASB & & 1 & 4 & 4 \\
\hline Total & & 48 & 20 & 51 \\
\hline
\end{tabular}

PRVC: pressure-regulated volume control; SIMV: synchronised intermittent mandatory ventilation; IMV: intermittent mandatory ventilation; VS: volume support; PS: pressure support; VC: volume control; PC: pressure control; BiPAP/ASB: biphasic positive airway pressure assisted spontaneous breathing. \#: manufacturers' details: Siemens ventilators are manufactured by SiemensElma, Solna, Sweden; Draeger ventilators by Drägerwerk, Lübeck, Germany; SLE 2000 by SLE, South Croydon, UK; and Infant Bear Cub by DRE, Louisville, KY, USA.

from baseline in table 3. During the 48 collections of EBC with humidification, there was a significant increase in PEEP and decreases in expiratory $V \mathrm{~T}, \mathrm{PEF}$ and PIF. No other parameters measured during collection of EBC with humidification changed significantly (table 3 ). The same analysis for the 20 collections with humidification discontinuation during sampling showed a significant increase in PEEP and a reduction in PEF (table 3).

Baseline values measured before and after EcoScreen connection to the ventilatory circuit did not vary significantly. None of the measured parameters changed significantly in the control group.

In order to exclude a gradual change during the 30-min collection period for any of the parameters, all data were analysed for linear trend using repeated-measures ANOVA with a post hoc test for linear trend. No linear trend was observed for any of the parameters analysed.

On two occasions (one EBC collection and one control), the total $50 \mathrm{~min}$ of recording was not achieved because the subject became clinically unstable. On both occasions, the accumulated secretions in the airways unrelated to the collection of EBC were thought to have caused the temporary deterioration. 


\begin{tabular}{|c|c|c|c|c|}
\hline \multirow[t]{3}{*}{ TABLE 3} & \multicolumn{4}{|c|}{$\begin{array}{l}\text { Changes in ventilatory and clinical parameters } \\
\text { during exhaled breath condensate (EBC) } \\
\text { collection with and without humidification }\end{array}$} \\
\hline & \multicolumn{2}{|c|}{ Humidification } & \multicolumn{2}{|c|}{ No humidification } \\
\hline & $\begin{array}{c}\text { Change }(95 \% \mathrm{Cl}) \\
\%\end{array}$ & $p$-value & $\begin{array}{c}\text { Change }(95 \% \mathrm{Cl}) \mathrm{p} \\
\%\end{array}$ & $p$-value \\
\hline Subjects n & 48 & & 20 & \\
\hline$V^{\prime} E L \cdot \mathbf{S}^{-1}$ & $-1.88(-5.10-1.33)$ & 0.24 & $-2.40(-5.50-0.62)$ & 0.11 \\
\hline 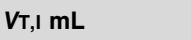 & $-0.3(-2.84-2.25)$ & 0.82 & $-0.97(-5.60-3.60)$ & 0.66 \\
\hline$V_{T, E} \mathrm{~mL}$ & $-4.24(-7.14--1.35)$ & 0.005 & $-0.44(-5.00-4.00)$ & 0.84 \\
\hline $\mathrm{PI}, \max \mathrm{cmH}_{2} \mathrm{O}$ & $1.39(-0.44-3.22)$ & 0.13 & $-0.67(-4.70-3.30)$ & 0.73 \\
\hline PEEP $\mathrm{cmH}_{2} \mathrm{O}$ & $6.52(5.18-7.86)$ & $<0.0001$ & $4.14(2.80-5.50)$ & $<0.0001$ \\
\hline PEF L. $\min ^{-1}$ & $-6.6(-9.64--3.55)$ & $<0.0001$ & $-6.14(-11.04--1.25)$ & 0.02 \\
\hline PIF L· min $^{-1}$ & $-5.55(-9.43--1.67)$ & 0.006 & $-0.6(-4.48-3.30)$ & 0.75 \\
\hline$f R$ breaths $\cdot \mathrm{min}^{-1}$ & $-11.16(-2.84-5.17)$ & 0.56 & $-3.98(-10.00-2.02)$ & 0.18 \\
\hline PET, $\mathrm{CO}_{2} \mathrm{kPa}$ & $1.24(-0.05-2.54)$ & 0.06 & $0.44(-1.10-2.00)$ & 0.55 \\
\hline$f_{c}$ beats $\cdot \min ^{-1}$ & $0.79(-0.67-2.26)$ & 0.36 & $-1.11(-2.43-0.21)$ & 0.09 \\
\hline mBP mmHg & $0.51(-1.30-2.32)$ & 0.57 & $-0.72(-3.50-2.06)$ & 0.59 \\
\hline $\mathrm{Sa}, \mathrm{O}_{2} \%$ & $-0.2(-0.72-0.31)$ & 0.42 & $0.0(-0.72-0.71)$ & 0.99 \\
\hline $\mathrm{F} 1, \mathrm{O}_{2}$ & $1.01(-0.03-2.04)$ & 0.06 & $-0.24(-0.59-0.11)$ & 0.27 \\
\hline $\mathrm{ICP} \mathrm{cmH}_{2} \mathrm{O}$ & $2.77(-3.02-8.56)$ & 0.18 & $-8.43(-26.56-9.70)$ & 0.27 \\
\hline
\end{tabular}

Percentage changes during 30 min of EBC collection are calculated relative to baseline: 100(difference/mean). Baseline values measured before and after EcoScreen connection to the ventilatory circuit did not vary significantly. $\mathrm{Cl}$ : confidence interval; $V^{\prime} \mathrm{E}$ : minute ventilation; $V_{T}$,I: inspiratory tidal volume; $V_{T}, E$ : expiratory tidal volume; PI,max: maximal inspiratory pressure; PEEP: positive end-expiratory pressure; PEF: peak expiratory flow; PIF: peak inspiratory flow $f_{\mathrm{R}}$ : respiratory frequency; $P \mathrm{ET}, \mathrm{CO}_{2}$ : end-tidal carbon dioxide tension; $f_{\mathrm{C}}$ : cardiac frequency; mBP: mean blood pressure; $\mathrm{Sa}_{1} \mathrm{O}_{2}$ : arterial oxygen saturation; $\mathrm{Fl}, \mathrm{O}_{2}$ : fraction of inspired oxygen; ICP: intracranial pressure.

Levels of 8-isoprostane in 18 nonhumidified and 44 humidified EBC samples were analysed. No 8-isoprostane could be detected in humidified EBC samples or in the sterile water used for humidification. Levels of 8 -isoprostane were above the reliable limit of detection of the assay in 10 out of the 18 nonhumidified samples (median (range) $4.7 \mathrm{pg} \cdot \mathrm{mL}^{-1} \quad(0$ $\left.5.8 \mathrm{pg} \cdot \mathrm{mL}^{-1}\right) ; \mathrm{p}<0.0001$; fig. 5).

\section{DISCUSSION}

The present study has demonstrated that collection of exhaled breath from ventilated infants and children is possible and safe using a commercially available collecting device. Both duration of collection and $V^{\prime} \mathrm{E}$ are important factors influencing the amount of EBC collected. Levels of 8-isoprostane were low and only above the reliable limit of detection of the assay once humidification of the inhaled gas mix was discontinued (fig. 5).

The attachment of a breath condenser resulted in small changes in ventilatory parameters, but this did not result in a change in clinical condition. In the opinion of the present authors, the physiological changes observed, although statistically significant, were not clinically significant, even in the very small babies. This is supported by the fact that all of the clinical parameters measured remained unchanged during the

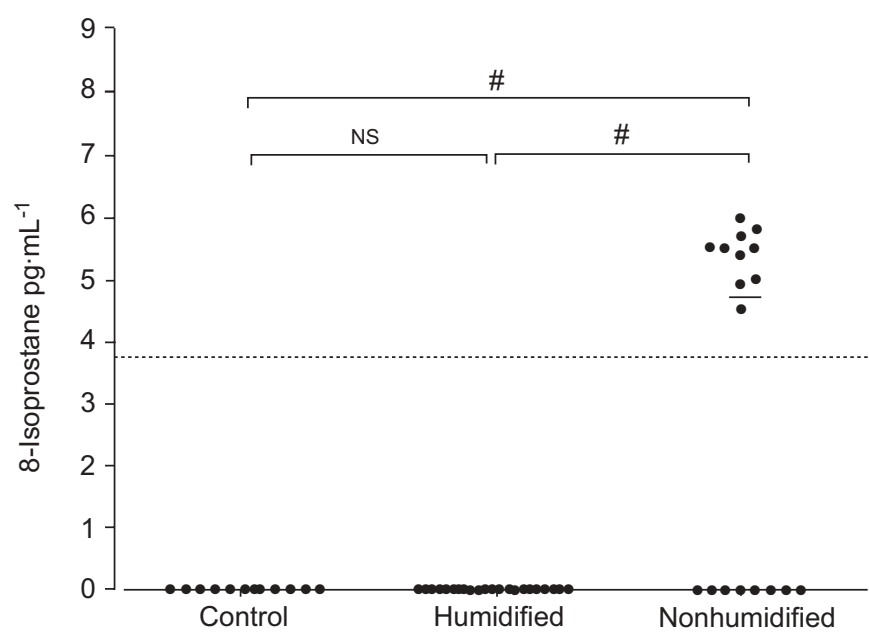

FIGURE 5. Levels of 8-isoprostane in exhaled breath condensate from paediatric subjects are significantly higher with nonhumidified ventilatory circuits (.....: detection limit of assay). Controls used water for inhalation (12 ventilatory circuits). Horizontal bars represent medians. NS: nonsignificant. ${ }^{\#}$ : $p<0.0001$.

observed period. Furthermore, discontinuation of humidification had no additional effect on the ventilatory and clinical parameters. The observed changes in ventilatory parameters most probably reflected a change in airflow characteristics within the tubing. HiTKA et al. [18] found that pressures in the expiratory limb of their collection device did not exceed $3 \mathrm{cmH}_{2} \mathrm{O}$ in their setting, but, to the present authors' knowledge, no study has assessed the influence of collection device on ventilatory settings.

Collection of EBC requires the connection of a device to the expiratory limb of the ventilatory circuit with the potential of increasing the resistance of the circuit. Indeed, the risk of expiratory flow limitation resulting from ice formation during EBC collection in the circuit has been described [10]. This raises the risk of hyperinflation of a ventilated patient. This was reproduced in an experimental model, and obstruction of the ventilatory system occurred only when collection times exceeded $2 \mathrm{~h}$ using the Jaeger EcoScreen. Choosing collection times of $<2 \mathrm{~h}$ obviates this problem. Other available exhaled breath collection devices may not be hampered by ice formation, but the present authors suggest that they are tested in an artificial model before being applied in a clinical setting.

There is also a potentially increased risk of accidental extubation during collection of EBC. This is due to the fact that a relatively immobile device is attached close to the endotracheal tube, and sudden movements of an intubated child may lead to dislodgement of the endotracheal tube. Careful attention and optimal positioning of the collecting device, together with secure fixation of the endotracheal tube, are important in minimising the risk. No accidental extubation occurred in the present series.

Although two subjects did not complete the study, this was felt to be unrelated to the collection of EBC. Both had developed increased lung secretions and required attention to their airways. This occurred during collection of EBC in one child and during collection of control data in the other. Children in 
paediatric intensive care units frequently become unstable and require medical attention and intervention. Minimal handling plays an important role in the management of these unstable children, and this takes priority over all noncritical procedures.

Identifying mechanisms of chronic inflammation and oxidative stress in the human respiratory tract may contribute to the understanding of lung pathologies and can be useful for monitoring their progression. Bronchial biopsy can be regarded as the gold standard for assessing lung inflammation; however, its invasive nature limits its use in many research settings. Instead, lung fluid has been used in the search for inflammatory mediators and markers of oxidative stress originating from lung tissue [1]. Bronchoalveolar lavage has been widely and effectively used to collect lung fluid from ventilated subjects [26], but questions remain regarding its correlation with bronchial biopsy results and repeatability [27]. Furthermore, although BAL is generally considered to be safe [27-29], transient adverse effects have been widely described [26, 30-34]. The recent dramatic increase in research interest in lung fluid has certainly been influenced by the fact that EBC collection has emerged as a potential noninvasive alternative to induced sputum and BAL fluid for measuring some inflammatory markers in nonventilated subjects. A safe application of EBC collection in ventilated children has potentially immense research implications and gives access to valuable information on changes in the composition of lung fluid in these subjects. Measurements in EBC, such as $\mathrm{pH}$, are robust and reproducible over time if analysed correctly, and are not affected by the degree of ventilation, prolonged storage of the sample or salivary $\mathrm{pH}$ [35].

However, despite its safety and noninvasiveness, EBC analysis, similar to BAL fluid, is hampered by methodological issues. Uncertainty regarding its origin and the dilution effect makes understanding of the findings difficult [36] and its interpretation controversial [37, 38]. Levels of 8-isoprostane above the detection limit of the assay were found in nonhumidified EBC samples alone, suggesting that dilution by the humidification system is an important factor in ventilated subjects. Many other unknown factors contribute to the dilution of EBC in nonventilated subjects. EFFrOs et al. [3] suggested that nonvolatile substances in EBC come from aerosolised droplets of extracellular lining fluid, and are diluted by water vapour from the epithelium. The effect of ventilation on droplet formation or on the evaporation of water is not well understood. Some, but not all, studies have reported little effect of minute volume ventilation on the concentration of exhaled makers [22, 23]. SCHLEISS et al. [24] found a falling hydrogen peroxide concentration with increasing expiratory flow in healthy volunteers and asthmatics. The possibility of contamination from the oropharynx has also been a concern [39]. Problems with too low a concentration of the measured substances have been reported if humidification continues during collection [17]. Previous studies on adult patients have avoided humidification by selecting the post-operative recovery phase for studying subjects [16] or by discontinuation of humidification [13].

It is concluded that exhaled breath condensate collection, with or without humidification of the inhaled gas, is a noninvasive tool that is well tolerated in ventilated infants and children.
Levels of 8-isoprostane above the reliable limit of the assay were detected in exhaled breath condensate samples from those subjects with no humidification of ventilatory circuits. Careful monitoring of clinical parameters is important, and safe limits for the collection times for a given device should be known. In order for exhaled breath condensate collection to become a useful clinical tool in the detection of lower airway inflammation in ventilated children, more sensitive and reliable methods of detecting these markers need to be developed.

\section{REFERENCES}

1 Kharitonov SA, Barnes PJ. Exhaled markers of pulmonary disease. Am J Respir Crit Care Med 2001; 163: 1693-1722.

2 Burmester M, Mok Q. How safe is non-bronchoscopic bronchoalveolar lavage in critically ill mechanically ventilated children? Intensive Care Med 2001; 27: 716-721.

3 Effros RM, Hoagland KW, Bosbous M, et al. Dilution of respiratory solutes in exhaled condensates. Am J Respir Crit Care Med 2002; 165: 663-669.

4 Gauvin F, Lacroix J, Guertin MC, et al. Reproducibility of blind protected bronchoalveolar lavage in mechanically ventilated children. Am J Respir Crit Care Med 2002; 165: 1618-1623.

5 Olivieri D, D'Ippolito R, Chetta A. Induced sputum: diagnostic value in interstitial lung disease. Curr Opin Pulm Med 2000; 6: 411-414.

6 Kharitonov SA. Exhaled markers of inflammatory lung diseases: ready for routine monitoring? Swiss Med Wkly 2004; 134: 175-192.

7 Baraldi E, Carraro S, Alinovi R, et al. Cysteinyl leukotrienes and 8-isoprostane in exhaled breath condensate of children with asthma exacerbations. Thorax 2003; 58: 505-509.

8 Lang JD, McArdle PJ, O'Reilly PJ, Matalon S. Oxidantantioxidant balance in acute lung injury. Chest 2002; 122: Suppl. 6, 314S-320S.

9 Pavord ID. Sputum induction to assess airway inflammation: is it an inflammatory stimulus? Thorax 1998; 53: 79-80.

10 Mutlu GM, Garey KW, Robbins RA, Danziger LH, Rubinstein I. Collection and analysis of exhaled breath condensate in humans. Am J Respir Crit Care Med 2001; 164: 731-737.

11 Effros RM, Dunning MB III, Biller J, Sharker R. The promise and perils of exhaled breath condensates. Am J Physiol Lung Cell Mol Physiol 2004; 287: L1073-L1080.

12 Baldwin SR, Simon RH, Grum CM, Ketai LH, Boxer LA, Devall LJ. Oxidant activity in expired breath of patients with adult respiratory distress syndrome. Lancet 1986; 1: 11-14.

13 Carpenter CT, Price PV, Christman BW. Exhaled breath condensate isoprostanes are elevated in patients with acute lung injury or ARDS. Chest 1998; 114: 1653-1659.

14 Gessner C, Hammerschmidt S, Kuhn H, et al. Exhaled breath condensate acidification in acute lung injury. Respir Med 2003; 97: 1188-1194.

15 Kietzmann D, Kahl R, Muller M, Burchardi H, Kettler D. Hydrogen peroxide in expired breath condensate of patients with acute respiratory failure and with ARDS. Intensive Care Med 1993; 19: 78-81. 
16 Moloney ED, Mumby SE, Gajdocsi R, et al. Exhaled breath condensate detects markers of pulmonary inflammation after cardiothoracic surgery. Am J Respir Crit Care Med 2004; 169: 64-69.

17 Cheah FC, Darlow BA, Winterbourn CC. Problems associated with collecting breath condensate for the measurement of exhaled hydrogen peroxide from neonates on respiratory support. Biol Neonate 2003; 84: 338-341.

18 Hitka P, Cerny M, Vizek M, Wilhelm J, Zoban P. Assessment of exhaled gases in ventilated preterm infants. Physiol Res 2004; 53: 561-564.

19 Nycyk JA, Drury JA, Cooke RW. Breath pentane as a marker for lipid peroxidation and adverse outcome in preterm infants. Arch Dis Child Fetal Neonatal Ed 1998; 79: F67-F69.

20 Horvath I, Hunt J, Barnes PJ, et al. Exhaled breath condensate: methodological recommendations and unresolved questions. Eur Respir J 2005; 26: 523-548.

21 Baraldi E, Ghiro L, Piovan V, et al. Safety and success of exhaled breath condensate collection in asthma. Arch Dis Child 2003; 88: 358-360.

22 McCafferty JB, Bradshaw TA, Tate S, Greening AP, Innes JA. Effects of breathing pattern and inspired air conditions on breath condensate volume, $\mathrm{pH}$, nitrite, and protein concentrations. Thorax 2004; 59: 694-698.

23 Montuschi P, Kharitonov SA, Ciabattoni G, et al. Exhaled 8isoprostane as a new non-invasive biomarker of oxidative stress in cystic fibrosis. Thorax 2000; 55: 205-209.

24 Schleiss MB, Holz O, Behnke M, Richter K, Magnussen H, Jorres RA. The concentration of hydrogen peroxide in exhaled air depends on expiratory flow rate. Eur Respir J 2000; 16: 1115-1118.

25 Cole TJ. Sympercents: symmetric percentage differences on the $100 \log _{\text {e }}$ scale simplify the presentation of $\log$ transformed data. Stat Med 2000; 19: 3109-3125.

26 Hertz MI, Woodward ME, Gross CR, Swart M, Marcy TW, Bitterman PB. Safety of bronchoalveolar lavage in the critically ill, mechanically ventilated patient. Crit Care Med 1991; 19: 1526-1532.
27 Shields MD, Riedler J. Bronchoalveolar lavage and tracheal aspirate for assessing airway inflammation in children. Am J Respir Crit Care Med 2000; 162: S15-S17.

28 Kotecha S. Bronchoalveolar lavage of newborn infants. Pediatr Pulmonol Suppl 1999; 18: 122-124.

29 Steinberg KP, Mitchell DR, Maunder RJ, Milberg JA, Whitcomb ME, Hudson LD. Safety of bronchoalveolar lavage in patients with adult respiratory distress syndrome. Am Rev Respir Dis 1993; 148: 556-561.

30 Klech H, Hutter C. Side-effects and safety of BAL. Eur Respir J 1990; 3: 939-940.

31 Ahrens P, Pabelick C, Schledt U, et al. Safety aspects of bronchoalveolar lavage in risk patients in childhood continuous end-expiratory $\mathrm{PCO}_{2}$ monitoring. Pneumologie 1998; 52: 157-160.

32 Belai YZ, Findlay RD, Lau AS, Walther FJ. Bronchoalveolar lavage in ventilated newborn infants: safety and tumor necrosis factor- $\alpha$ activity. J Perinatol 1997; 17: 360-365.

33 Balk RA, Bradsher RW Jr, Jacobs RF, et al. Bacteremia during bronchoalveolar lavage. South Med J 1986; 79: 1496-1498.

34 Whittle AT, Davis M, Johnson PR, Leonard RC, Greening AP. The safety and usefulness of routine bronchoscopy before stem cell transplantation and during neutropenia. Bone Marrow Transplant 1999; 24: 63-67.

35 Vaughan J, Ngamtrakulpanit L, Pajewski TN, et al. Exhaled breath condensate $\mathrm{pH}$ is a robust and reproducible assay of airway acidity. Eur Respir J 2003; 22: 889-894.

36 Hyde RW. "I don't know what you guys are measuring but you sure are measuring it!" A fair criticism of measurements of exhaled condensates? Am J Respir Crit Care Med 2002; 165: 561-562.

37 Gaston B. Breath condensate analysis: perhaps worth studying, after all. Am J Respir Crit Care Med 2003; 167: 292-293.

38 Effros RM, Gaston B, Mutti A, et al. Saving the breath condensate approach. Am J Respir Crit Care Med 2003; 168: 1129-1130.

39 Griese M, Noss J, Bredow CC. Protein pattern of exhaled breath condensate and saliva. Proteomics 2002; 2: 690-696. 